\title{
Diferenciais de preço no comércio colonial não servem como medida de margens de lucro
}

\author{
André Arruda Villela*
}

\section{Introdução}

O presente artigo é, assumidamente, uma tréplica a texto de autoria do Prof. José Jobson Arruda, publicado em dezembro de 2014 pela Topoi. ${ }^{1}$ Naquele trabalho, Arruda respondeu a críticas que eu fizera ao chamado Modelo do Antigo Sistema Colonial, em artigo de 2011, publicado na mesma revista. ${ }^{2}$

Foram muitas as objeçóes do Prof. Jobson a meu trabalho, tanto à forma como à substância do artigo. No que se segue irei reagir aos seus principais pontos, começando pela ressalva a meu estilo argumentativo. As questóes de conteúdo serão tratadas nas seções subsequentes.

Segundo Arruda, o meu uso, nas conclusóes do artigo de 2011, de termos como indicios e provavelmente revelaria insegurança, hesitação de minha parte. Cobrava-me, o meu crítico, um posicionamento mais categórico após as minhas proposiçóes "contundentes” e "rascantes" (p. 708-9). Procurarei ser mais explícito em minhas afirmações ao longo de toda a presente tréplica.

Partilho com o Prof. Jobson o desconforto com aquilo que os anglo-saxóes denominam, com a habitual objetividade, weasel words ("palavras covardes", em analogia às doninhas, animais sabidamente furtivos). Procuro sempre evitar termos como indicar, sugerir ou possivelmente - exceto quando eles se fazem indispensáveis. E foi este, justamente, o caso do artigo que eu escrevera, com duras críticas àquilo que julgo ser a pouca sustentação teórica e factual do Modelo do Antigo Sistema Colonial. Baseado que estava integralmente em literatura secundária — e, portanto, sem que eu próprio tivesse feito trabalho de pesquisa

DOI - http://dx.doi.org/10.1590/2237-101X016031018

* Doutor em História Econômica pela University of London, UK, e professor na Fundação Getulio Vargas (EPGE /FGV-RJ). Rio de Janeiro, RJ, Brasil. E-mail: andre.villela@fgv.br.

Sou grato a Marcelo de Paiva Abreu, Carlos Accioly e Teodoro Koracakis pelos comentários à versão preliminar do texto.

${ }^{1}$ Ver ARRUDA, José Jobson de A. Superlucros: a prova empírica do exclusivo colonial. Topoi, v. 15, n. 29, p. 706-718, jul./dez 2014. O autor parece indeciso quanto à natureza de seu artigo. De "réplica", no Resumo, deixa de sê-lo logo na abertura, transformando-se em um "convite". Tomo-o como a réplica que é e reajo a ele na presente tréplica.

2 Ver VILLELA, André A. Exclusivo metropolitano, “superlucros” e acumulação primitiva na Europa pré-industrial. Topoi, v. 12, n. 23, p. 706-718, jul./dez. 2011. 
detalhado que me permitisse calcular corretamente margens de lucro no comércio de Portugal com o Brasil - não me senti, então, à vontade para ser mais categórico em minhas conclusôes, conforme me cobrou Arruda.

A presente tréplica tampouco se baseia em pesquisa primária de minha autoria. Muda, porém, o estilo da argumentação. Atendendo ao convite de meu interlocutor, serei mais direto. Como se verá, reafirmo, em sua essência, minhas principais críticas ao Modelo.

O estilo direto da tréplica, espero, não deixará margem para ambiguidades.

\section{Colocando as coisas no lugar}

Antes de adentrar na discussão dos três eixos principais do Modelo (monopólio, "superlucros" e acumulação primitiva de capital), reajo a alguns pontos levantados por Arruda nas páginas iniciais de seu artigo e que exigem posicionamento inequívoco de minha parte.

- "(Villela) conclui, por antecipação, que o exclusivo não era absoluto [...]; que não havia superlucros [...]; e que era improvável a conexão entre esses recursos e o deslanchar da revolução industrial na Europa" (p. 707). Como assim, "por antecipação"?!? O próprio Arruda remete o leitor à p. 16 de meu artigo, isto é, nas minhas Conclusões e após 15,5 páginas de argumentos. Ele pode até não ter gostado de meus argumentos, mas falta - no mínimo - com a lógica ao afirmar que concluí algo "por antecipação".

- Arruda afirma que, em meu artigo, fiz-me de "[...] uma espécie de porta-voz (dos historiadores ditos 'intérpretes alternativos')" (p. 707). Que fique claro: não sou "porta-voz" de ninguém. Não faço parte de "igrejinhas" ou "patotas" acadêmicas. Falo e escrevo o que eu penso, sem compromisso com este ou aquele grupo.

- O Prof. Jobson afirma, também, que eu desqualifico "monopólios" como "conceito válido para interpretar a economia colonial" (p. 707). Isto é falso. Em momento algum desqualifico o conceito em si. O que fiz - e reitero aqui - foi questionar a existência de poder de monopólio efetivo dos agentes portugueses no comércio com o Brasil. A falta de tal poder - amplamente documentada na literatura ${ }^{3}$ — enfraquece em muito a noção de que haveria "superlucros" a serem obtidos em tal atividade. ${ }^{4}$

- Arruda enxerga hesitação quando digo faltar evidência de relação entre transferência de recursos do comércio Portugal-Brasil e a industrialização inglesa. Afirma, de for-

\footnotetext{
${ }^{3}$ Veja-se, por exemplo, a correspondência do comerciante Francisco Pinheiro, reunida em LISANTI, Luis. Negócios coloniais: uma correspondência comercial do século XVIII. Brasília: Ministério da Fazenda; São Paulo: Visão, 1973.

${ }^{4}$ Neste particular, estou totalmente de acordo com meu interlocutor, quando afirma que "[...] a prática do exclusivo não implicava a desaparição completa da concorrência interimperial [...]” (p. 707). Meu ponto, na verdade, remete à acirrada concorrência (o contrário de monopólio, portanto) que existia entre os agentes de Portugal atuando no comércio com a colônia — uma concorrência intraimperial, por assim dizer.
} 
ma mais contundente, que recorri a "[...] ilaçôes retóricas alicerçadas em indícios pontuais referidas a experiências históricas alheias vazadas em exercícios contrafactuais que, por via da dedução lógica, convertem-se em prova empírica e verdade histórica. Filigranas." (p. 709). "Ilaçôes retóricas" e "filigranas", ao que parece, são termos utilizados pelo Prof. Jobson para (des)qualificar argumentos com os quais não concorda. Ao contrário do que afirma, porém, não me baseei em "indícios pontuais" para criticar a lógica do Modelo do Antigo Sistema Colonial. Ao leitor interessado, basta ir (ou voltar) a meu artigo de 2011 e constatar que ali expus, didaticamente, minha crítica ao referido modelo, segundo seus três eixos principais (exclusivo, superlucros e acumulação primitiva, cada um deles tratado em seçôes distintas, mas logicamente concatenadas). E o fiz com base, sim, em literatura secundária consagrada na área da história da América portuguesa e da Europa em geral (com destaque para a história da Revolução Industrial), complementada por teoria econômica elementar. E qual o problema de recorrer à "experiência histórica alheia"? Por acaso ela não ajuda a entendermos a nossa própria história - sobretudo em se tratando de fenômeno pan-europeu, como o foi a colonizaçáo do Novo Mundo no início da Era Moderna? O meticuloso trabalho, por mim citado, de G. Daudin — que, aliás, não mereceu qualquer menção de meu interlocutor - versando sobre o comércio da França com suas colônias no Caribe, e que estima em 6\% a margem de lucro média daquela atividade, deveria servir, ao menos, para encararmos com ceticismo as referências de Arruda a "superlucros" de ordem de magnitude bem diversa (dois ou três dígitos). ${ }^{5}$

Finalmente - e antes de passar à discussão sobre os chamados "superlucros" —, respondo a uma provocação de meu interlocutor. Arruda tacha de "irônico" meu convite aos adeptos do Modelo para que o dotem de "sustentação (empírica) mais robusta" (p. 709). Fiz tal convite de boa-fé, tendo como contraponto não o meu próprio artigo — integralmente baseado que estava na literatura secundária —, mas sim o notável esforço de pesquisa em arquivos realizado nos últimos 15-20 anos por historiadores igualmente críticos do Modelo do Antigo Sistema Colonial. ${ }^{6}$ Renovo aqui tal convite.

\footnotetext{
${ }^{5}$ Quanto aos tais “exercícios contrafactuais” de que sou acusado de endossar, trata-se, na verdade, da menção que fiz (p. 15) a um único exercício apenas (no singular, portanto), realizado por D. McCloskey, e que conclui pela pouca importância dos mercados externos para o crescimento da economia britânica entre 1780-1860. Não usei tal referência como base única de minha argumentação, mas apenas como ilustração pontual de visão existente em círculos acadêmicos respeitados, que não veem as exportaçôes manufatureiras inglesas como decisivas para a Revolução Industrial.

${ }^{6}$ Para o estado da arte deste programa de pesquisa, ver os diversos capítulos reunidos nos três volumes de FRAGOSO, João Luís Ribeiro; GOUVÊA, Maria de Fátima (Orgs.). O Brasil colonial. Rio de Janeiro: Civilização Brasileira, 2014.
} 


\section{Calculando a lucratividade do comércio colonial}

Os huteritas são grupo religioso pouco conhecido. Trata-se de um ramo dos anabatistas que se concentra, atualmente, na região do meio-oeste dos Estados Unidos e Canadá, totalizando pouco menos de 50 mil habitantes. Os demógrafos, porém, têm um interesse particular nos huteritas, por conta de suas características demográficas atípicas: apresentam famílias que, historicamente, contavam com 10 filhos, em média, o que envolve uma taxa de natalidade próxima de 50/1.000 habitantes (ou 5\% a.a.). Sendo assim, considera-se, em demografia, que, na ausência de fluxos migratórios, populaçóes humanas exibem uma taxa-limite de expansão igual aos 5\% anuais apresentados pelos huteritas.

A economia, ao contrário da demografia, não opera com esta noção de um teto para o crescimento de variáveis tais como o faturamento de empresas, crescimento do PIB, aumento do emprego etc. Mas isso não quer dizer que não existam limites lógicos à expansão destas (e outras) variáveis econômicas. ${ }^{7}$ Isso se aplica, também, ao caso de taxas de lucro.

A taxa de lucro, não custa lembrar, é definida como a relação entre o lucro obtido em determinada atividade e o capital nela empregado. O lucro, por sua vez, nada mais é que a diferença entre o total de receitas e o total de despesas de um negócio. Dito isso, como interpretar os números calculados por Arruda em seu trabalho de 1980? Seriam eles, de fato, "superlucros", que caracterizariam o comércio de Portugal com o Brasil na passagem do século XVIII para o XIX?

Um ponto de partida útil para abordarmos esta questáo é a definição dos preços das mercadorias constantes das "Balanças de Comércio" utilizadas pelo Prof. Jobson em seu estudo. Aqui, o autor cita, na íntegra, Adriano Balbi, autor de Essai Statistique sur le Royaumme de Portugal et d'Algarve, comparé aux Autres États de l'Europe:

O valor dos artigos de importaçáo (em Portugal) foram (sic) deduzidos dos preços médios dos primeiros custos nos portos de origem, aumentados dos direitos de saída, despesas de comissóes e fretes, mas sem contar os direitos pagos na entrada dos portos de Portugal. O preço das mercadorias exportadas foram calculados (sic) juntando-se ao preço médio de custo as despesas de comissóes, os direitos de saída e outras despesas até o embarque. ${ }^{8}$

A partir daí, Arruda calculou, para o caso de produtos coloniais posteriormente exportados por Portugal para terceiros mercados (açúcar, tabaco etc.), a diferença entre o preço de saída do Brasil e de reexportaçáo a partir de Portugal; no caso de artigos manufaturados importados por Portugal e revendidos na colônia (ferro em barra, por exemplo), a diferença

\footnotetext{
${ }^{7}$ Por exemplo, náo é razoável se esperar que o PIB per capita de um país cresça, digamos, $100 \%$ de um ano para o outro ou, ainda, a existência de uma taxa de desemprego de $0 \%$.

${ }^{8}$ Ver ARRUDA, José Jobson de A. O Brasil no comércio colonial. São Paulo: Ática, 1980, p. 349.
} 
entre o preço de importação em Portugal e o preço de importação no Brasil; e, por fim, em se tratando de artigos metropolitanos (como o azeite), a diferença entre o preço de exportação em Portugal e o preço de sua entrada na colônia.

Há, pelo menos, três problemas que impedem a interpretação desses diferenciais de preços como sendo reveladores de lucros e, mais ainda, "superlucros". O primeiro deles diz respeito às despesas (custos) embutidas nesses preços. Segundo Arruda, as principais despesas incorridas pelos comerciantes metropolitanos já estariam incluídas nesses preços. Em meu artigo de 2011, afirmei que não. Essencialmente, chamava atenção para custos de capital e de mão de obra não captados nos dados dos "Balanços", mas que teriam que ser cobertos pela (eventual) venda das mercadorias transportadas. Mantenho a minha opiniáo original.

Um segundo problema envolve, especificamente, a forma como são lançados, nos "Balanços", os preços dos produtos importados e exportados por Portugal, e que serviram de base para os cálculos do Prof. Jobson.

Peguemos o caso de um comerciante que, em 1798, trouxesse algodáo brasileiro para Portugal. ${ }^{9}$ De acordo com a Tabela 52 do livro de Arruda, naquele ano tal mercadoria apresentou preço médio de 6.848 réis/arroba nos portos do Brasil..$^{10}$ Suponhamos que este mesmo comerciante enviasse este algodáo para o mercado europeu. $\mathrm{O}$ preço médio de exportação (a partir de Portugal), neste caso, foi de 11.581 réis por arroba (ver Tabela 53). Da diferença entre estes dois preços (isto é, 4.733 réis), Arruda estimou um "superlucro" de 69,1\% naquele ano $(=(4.733 / 6.848) * 100)$.

Ocorre que, sobre o preço de 6.848 réis na colônia, iriam incidir, no transporte daquele algodão para Portugal, direitos de saída, despesas de comissão e frete, até a sua chegada a um porto metropolitano. Ali, após recolher os direitos de entrada, o comerciante teria que pagar, ainda, "[...] despesas de comissóes, os direitos de saída e outras despesas até o embarque" daquele artigo destinado à reexportação.

Ora, fica claro, neste exemplo, que o "lucro" de nosso comerciante hipotético nesta operação não é dado, como quer Arruda, pela diferença entre 11.581 réis e 6.848 réis, mas, sim, entre 11.581 réis líquidos de uma série de despesas em Portugal (cujo montante desconhecemos) e 6.848 réis acrescidos de direitos de saída do Brasil, despesas com comissão e frete e direitos de importação em Portugal (totalizando um valor que, igualmente, desconhecemos). Ou seja, por um número, necessariamente, muito menor que 4.733 réis e, portanto,

\footnotetext{
${ }^{9} \mathrm{O}$ raciocínio que se segue se aplica, igualmente, a qualquer um dos produtos coloniais reexportados por Portugal.

${ }^{10}$ Ver ARRUDA, José Jobson de A. O Brasil no comércio colonial, op. cit., p. 368. Ao discutir o caso do açúcar branco, logo no início de sua análise de cada um dos produtos de exportação colonial, Arruda afirma: “[...] seria de se esperar que os preços internos da Colônia fossem mais constantes do que aparecem neste gráfico [...]. Pelo contrário, o que notamos é uma certa sincronia entre as flutuaçóes dos preços de exportação e de reexportação, na qual se percebe uma razoável margem de lucro, resultante da diferença entre o preço de compra (da Colônia) e venda (às Naçôes Estrangeiras)" (grifos meus). Ibidem, p. 355. Como se nota, os "preços de exportação" utilizados pelo Prof. Jobson em seus cálculos são os dos produtos coloniais nos portos brasileiros.
} 
um diferencial muito inferior aos $69,1 \%$ postulados por meu interlocutor. Tal resultado, é claro, se estende a todos os demais produtos brasileiros reexportados pela metrópole, e revela superestimação dos ditos "superlucros" de Arruda.

Os problemas não param aí, porém. Mais importante até que os dois pontos anteriores - e diretamente relacionada a eles - é uma hipótese heroica adotada implicitamente (ou, mesmo, inadvertidamente) por meu crítico, qual seja, a de que todas as mercadorias constantes dos "Balanços" foram, efetivamente, vendidas. E não apenas vendidas, como, também, comercializadas aos preços a que foram registradas nas alfândegas do reino.

É possível imaginar que inexistisse "encalhe" de mercadorias no comércio colonial ou que o preço a que determinado artigo era comercializado independesse das condiçóes de oferta no mercado relevante? Será que não fazia diferença se, por exemplo, ao tentar vender determinado artigo no Brasil, o comerciante se deparasse com um mercado já saturado? $\mathrm{Ou}$ cujos gostos houvessem mudado e, com isso, desaparecido a demanda por artigos que ele trouxera ao mercado? Não se pode esquecer, tampouco, de avarias e deterioração sofridas por mercadorias perecíveis (alimentos, por exemplo). ${ }^{11}$

Posto de outra forma: será que não havia a possibilidade de prejuízo no comércio colonial? Da forma como é apresentado por Arruda, não. Toda e qualquer operaçáo comercial realizada - e registrada nos "Balanços" - traria, por construção, "lucros" aos comerciantes metropolitanos. Isto porque tais lucros foram calculados, por Arruda, como sendo a diferença entre um preço menor (na saída de um porto) e outro maior (na entrada em outro porto). Ou seja, um resultado positivo. Por definição.

O que se quer ressaltar aqui é que - além de não captarem todos os custos (despesas) inerentes ao comércio colonial — os dados dos "Balanços" não se prestam ao cômputo das receitas efetivas dos comerciantes metropolitanos nos negócios com o Brasil. Isto porque o preço de (eventual) venda de uma mercadoria não corresponde, necessariamente, àquele registrado nas alfândegas. Sendo assim — e contrariamente ao que pretende Arruda - , aquela importante fonte estatística, por si só, não traz informaçôes que nos permitam calcular com algum grau de precisão os lucros obtidos no comércio colonial.

Mas nem tudo está perdido. Ainda que não possamos medir os lucros do comércio colonial apenas com base nos "Balanços", uma simples análise de sensibilidade nos dá uma noção aproximada de sua ordem de grandeza. E o resultado de tal análise lança dúvidas sobre o quão razoável é a interpretação que o Prof. Jobson dá a seus números, por ele denominados de "superlucros". Se não, vejamos.

Voltando ao caso dos huteritas, será razoável imaginarmos taxas de lucro anuais da ordem de $100 \%$ a.a. no comércio colonial, em linha com os "superlucros" desta ordem de

\footnotetext{
${ }^{11}$ Para a imprevisibilidade intrínseca ao comércio colonial e a ocorrência ocasional de prejuízo — no caso, envolvendo os negócios do comerciante Francisco Pinheiro com o Brasil —, ver HONDA, Laercio M. Francisco Pinheiro: as atividades de um comerciante de grosso trato na América Portuguesa (1703-1749). Dissertação (mestrado) — Instituto de Economia, Unicamp, 2004.
} 
grandeza supostamente obtidos, segundo Arruda, na venda de tabaco brasileiro na Europa? Certamente que não. E se usássemos, em vez do tabaco, os superlucros médios do comércio da Bahia com Portugal? Tais lucros — calculados em 59,12\% $\%^{12}$ — seriam mais plausíveis?

Imaginemos o caso de um comerciante que operasse apenas no comércio da Bahia com a metrópole e realizasse uma operação em determinado ano. Caso ele embarcasse para Portugal uma carga composta por produtos na exata proporçáo do peso destes na pauta provincial, ele se depararia com diferencial de preço ("lucro", segundo Arruda) de 59,12\%. "Superlucros!", diriam os adeptos do Modelo. Agora, suponhamos que este mesmo comerciante, animado com tal diferencial, resolvesse reinvestir tais recursos em igual operação no ano seguinte - e ao longo dos 16 anos examinados pelo Prof. Jobson (1796-1811). Qual seria, neste caso, o seu "lucro"? Simples: $(1,5912)^{15}=1.061$ vezes. Ou mais de 100.000\%! Pergunta: tais números fazem sentido? Não. Da mesma forma que não faz sentido um crescimento demográfico de 100\% a.a. ou taxa de investimento de $90 \%$ do PIB...

Por tais razóes, preferi, em meu artigo de 2011, usar como parâmetros mais plausíveis para a rentabilidade do comércio colonial estudos de outras experiências contemporâneas. Vali-me do exemplo da Companhia das Índias Orientais holandesas (VOC) por entender que se tratava do caso de uma empresa, reconhecidamente, bem-sucedida, cuja rentabilidade seria passível de comparação com a experiência do comércio de Portugal com o Brasil.13

Complementei meus argumentos quanto ao exagero implícito em se tomar diferenciais de preços como sinônimo de lucratividade reportando-me a detalhado estudo de G. Daudin sobre o comércio colonial francês - e que encontrou rentabilidade média de $6 \%$ a.a. ${ }^{14}$ Resta aguardar estudo igualmente detalhado para o caso do comércio de Portugal com a sua colônia na América.

\footnotetext{
${ }^{12}$ Considerando-se as exportaçôes da Bahia ponderadas pelo peso de cada artigo (e respectivo diferencial de preço) na pauta daquela capitania.

${ }^{13}$ Admito que náo se trata de um exemplo ideal, dada a diferença de produtos transacionados (receitas) e a distância muito maior (despesas) no caso holandês. Diferentemente do que afirma Arruda (p. 712), não consegui encontrar (ao menos na versão retirada da internet) crítica de Gelderblom aos cálculos de rentabilidade da VOC feitos por de Vries e van der Woude e por mim reproduzidos. Ver de VRIES, Jan; van der WOUDE, Ad. The First Modern Economy: success, failure, and perseverance of the Dutch economy, 1500-1815. Cambridge: Cambridge University Press, 1997; e GELDERBLOM, Oscar. The Organization of Long-Distance Trade in England and the Dutch Republic, 1550-1650. Mimeo, 2008. Disponível em: <http://vkc.library.uu.nl/vkc/seh/ research/Lists/Working\%20Papers/Attachments/16/Gelderblom_OrganizationTrade_2008.pdf>.

${ }^{14}$ Tal número (6\%) não deve ser visto como um "teto" mas, sim, como um parâmetro, uma ordem de grandeza (no caso, de apenas um dígito) que se pode, razoavelmente, atribuir à margem de lucro obtida pelos comerciantes metropolitanos no comércio colonial. Ver DAUDIN, Guillaume. Profitability of Slave and Long-Distance Trading in Context: the case of eighteenth-century France. Journal of Economic History, v. 64, n. 1, p. 144-171, March 2004 e, do mesmo autor, Comment Calculer les Profits de la Traite?. Mimeo, 2002. Disponível em: <http://spire.sciences-po.fr/hdl:/2441/691/resources/cfi-art-gd-outremer2002draft.pdf>.
} 


\section{Comércio colonial e industrialização europeia}

Antes de encerrar, teço breves consideraçóes a respeito do juízo que Arruda fez da última parte de meu artigo de 2011, em que apontei a falta de evidências empíricas que comprovassem a alegada (pelos adeptos do Modelo do Antigo Sistema Colonial) transferência de lucros do comércio luso-brasileiro para o financiamento de investimentos na Inglaterra à época da Revolução Industrial.

Ao criticar o tratamento que dei à questáo, reconhecidamente polêmica, meu interlocutor não resistiu a lançar mão de artimanha conhecida, qual seja, sugerir que eu tivesse a pretensão de estar trazendo alguma novidade, algo inédito, para o debate quando, na realidade, tratar-se-ia, segundo ele, de mera "reciclagem" (p. 713)..$^{15}$

Qualquer leitor poderá verificar que em momento algum afirmei, nem tampouco dei a entender, estar propondo algo de novo nesta área. Fiz questão, isso sim, de deixar clara a natureza complexa e controversa do tema, tendo citado diversos autores respeitados e que mantêm opiniâo diversa sobre a relação entre o comércio colonial e o advento da Revolução Industrial britânica. ${ }^{16}$

Quando nos referimos à "dinâmica" do Antigo Sistema Colonial, estamos discutindo, no fundo, o fenômeno do crescimento econômico. Queremos saber como e por que a renda per capita na América portuguesa cresceu (pouco) como cresceu, ou qual teria sido a influência de suas relaçôes comerciais com a metrópole no desempenho econômico desta última ou, mesmo, da Inglaterra. ${ }^{17}$

\footnotetext{
${ }^{15}$ Com relação a este tema, o Prof. Jobson parece especialmente contrariado pela mudança de opinião do renomado historiador econômico David Landes. De alguém que já acreditou no papel central que a exploração colonial teria exercido para o desenvolvimento econômico europeu, Landes passou à opiniáo de que a Revolução Industrial ocorrera, largamente, de forma independente da colonização (p. 716). Nenhuma palavra de Arruda, porém, sobre a notória mudança de posição, neste debate, de outro respeitado historiador econômico - Patrick O’Brien. Um dos promotores (juntamente com Leandro Prados de la Escosura), segundo meu crítico, de "catilinária orquestrada (no XII Congresso Internacional de História Econômica) contra a tese da exploração colonial e seu contributo para a industrialização” (p. 716), O’Brien vem, nos últimos anos, revendo a sua posição original, passando a enxergar um papel para a exploração colonial no deslanchar industrial britânico. Ver, por exemplo, O'BRIEN, Patrick. The Formation of States and Transitions to Modern Economies: England, Europe, and Asia compared. In: Neal, Larry; Williamson, Jeffrey (Orgs.). The Cambridge History of Capitalism. Cambridge: Cambridge University Press, v. I (The Rise of Capitalism: from Ancient Origins to 1848), 2014; Mercantilism and Imperialism in the Rise and Decline of the Dutch and English Economies. De Economist, n. 148, p. 469-501, 2000; e Inseparable Connections: Trade, Economy, Fiscal State and the Expansion of Empire, 1688-1815. In: MARSHALL, Peter James (Org.). The Oxford History of the British Empire, vol. 2 (The Eighteenth Century). Oxford: Oxford University Press, 1998.

${ }^{16}$ Uma contribuição recente ao debate, argumentando que a Revolução Industrial jamais teria ocorrido sem o concurso do comércio exterior, da escravidão e do algodão, é BECKERT, Sven. Empire of Cotton: a global history. Nova York: Alfred A. Knopf, 2014.

${ }^{17}$ Aproveito aqui para esclarecer um mal-entendido. Quando, à p. 15 de meu artigo de 2011, afirmei que o comércio exterior passou a ser mais "decisivo" para a economia europeia somente após a Revolução Industrial, queria destacar o fato de a economia mundial ter se tornado mais integrada e aberta apenas no século XIX.
} 
O crescimento econômico pode decorrer de uma maior incorporação de fatores (terra, trabalho, capital físico ou humano) ao processo produtivo, pela via dos ganhos de eficiência (produtividade), ou da combinação de ambos. A colonização do Novo Mundo envolvia, sobretudo, a primeira forma de crescimento, ao adicionar vastos recursos naturais (sendo a terra o mais importante) e pessoas à economia europeia. $\mathrm{O}$ resultado, porém, não alterou em muito o panorama generalizado de crescimento baixo/nulo da renda per capita da maior parte dos países no início da Era Moderna - exceçấo feita à Holanda e Inglaterra, que lograram alguma expansão desta variável antes de $1800 .^{18}$

O maior grau de comercialização das economias holandesa e inglesa à época — do qual a empresa colonial era uma das componentes - ajuda a explicar a excepcionalidade destes dois países em um período em que a renda por habitante pouco avançou no restante do mundo. $\mathrm{Na}$ prática, tem-se, portanto, que a empresa colonial potencialmente permitia algum ganho de eficiência (e, portanto, de renda) às economias metropolitanas, via melhor alocação de recursos (ganhos estáticos) ou, até, ganhos de eficiência produtiva através de efeitos de escala na produção de determinados artigos ou provisão de serviços comerciais, financeiros etc. ${ }^{19}$

Contudo, é igualmente possível que a atividade colonial tenha acarretado mais perdas do que ganhos, seja pelos custos incorridos (incluindo a destruição/captura de mercadorias e investimentos na aventura colonial), ou pela má alocação de recursos decorrente da predominância de inúmeros monopólios e elevada taxação em um contexto mercantilista.

Em suma, o que se deseja enfatizar aqui é que não é possível afirmar a priori que a colonização trouxesse, necessariamente, ganhos líquidos às economias das metrópoles colonizadoras (ainda que pudesse, é claro, ser lucrativa para parte da classe mercantil). ${ }^{20}$ Mais

Neste contexto, o comércio internacional passou a ter mais influência sobre as economias domésticas do que era o caso nos séculos anteriores, quando as economias nacionais eram mais fechadas. Concordo com Arruda que, em contrapartida, no século XIX os setores industrial e financeiro se tornaram, relativamente, mais importantes do que o comércio exterior no sentido de conferir dinamismo às economias do chamado "Norte". ${ }_{18}$ Para uma discussão recente deste tópico, ver BROADBERRY, Stephen; CAMPBELL, Bruce M. S.; KLEIN, Alexander; OVERTON, Mark; van LEUWEN, Bas. British Economic Growth, 1270-1870. Cambridge: Cambridge University Press, 2015, especialmente o cap. 10.

${ }^{19}$ Ainda no tocante a este tema controverso, Arruda critica sem meias palavras a literatura estrangeira que vê com ceticismo a noção de que haveria relação causal entre a exploração colonial e o desenvolvimento econômico da Europa. Para ele, tal ceticismo funcionaria como "[...] uma espécie de catarse, de purgação de sentimento de culpa entranhado na consciência europeia, cujo significado último é: nada devemos porque nunca exploramos" (p. 708). É possível que sim. Como também não se pode descartar a hipótese de que a postulação de nexo causal ligando o enriquecimento europeu ao atraso econômico de outras partes do mundo decorra de certo complexo de inferioridade e da busca por responsabilizar "o outro" por nossas próprias mazelas. Sinceramente, não sei dizer.

${ }^{20}$ Ao que parece, este foi o caso dos impactos limitados do colonialismo sobre o crescimento econômico da Espanha e da França no início da Era Moderna. Para uma discussão recente, ver PALMA, Nuno. Sailing Away from Malthus: intercontinental trade and European economic growth, 1500-1800. London School of Economics and Political Science. Economic History Working Papers, n. 210, 2014. Cumpre ressaltar que a mensuração dos impactos econômicos da atividade colonial é tarefa extremamente complexa do ponto de vista empírico, posto que os efeitos da exploração do Novo Mundo vão muito além de eventuais lucros 
ainda, a alegada relação entre lucros obtidos no comércio luso-brasileiro e o financiamento da Revolução Industrial britânica - relação esta que está no cerne do Modelo do Antigo Sistema Colonial — não apenas carece, como afirmei em meu artigo de 2011, de comprovação empírica como sequer figura na vasta literatura estrangeira especializada sobre o assunto. Este último fato parece-me revelador.

\section{Considerações finais}

O Modelo do Antigo Sistema Colonial não é persuasivo, malgrado o esforço de Arruda em convencer-me do contrário. Ele náo convence por depender, crucialmente, de serem verdadeiros os três elementos a que me referi em meu artigo original: o exclusivo metropolitano, os superlucros e a transferência, para a Inglaterra, desses lucros, a fim de servirem de capital financiador da Revolução Industrial.

Reitero aqui o que afirmei no trabalho de 2011:

- o monopólio (exclusivo metropolitano) no comércio com o Brasil existiu de jure para a metrópole portuguesa como um todo, mas náo de facto para os comerciantes metropolitanos no dia a dia. E, para efeito da capacidade de se extrair rendas extraordinárias da colônia, é este último que conta;

- aquilo que Arruda insiste em denominar "superlucros" não o são. São, na realidade, elevados diferenciais de preços entre a entrada e saída de mercadorias em portos do Reino, diferenciais estes que jamais poderiam proporcionar margens de lucro anuais da ordem de 2-3 dígitos, como quer o meu crítico; e

- em nenhum momento fica claro como se dava a transferência dos supostos "superlucros" de Portugal para a Inglaterra, onde teriam ajudado em acumulação primitiva de capital que muitos especialistas julgam não ter sido necessária para financiar os investimentos nas primeiras fábricas modernas.

Ironicamente, Arruda incorre no mesmíssimo erro que (de maneira acertada) identifica em muitos dos economistas historiadores que, segundo ele "[...] por vezo de ofício, tendem a forçar a teoria sobre a história” (p. 708). Afinal, o que é o Modelo do Antigo Sistema Colonial se não algo que parte de uma teoria de fundo marxista/mercantilista - segundo a qual a riqueza de uns poucos países é obtida à custa da pobreza de muitos outros — para, aí então, sair à procura de evidências históricas para corroborar tal artigo de fé? Dentre tais evidências estariam, justamente, a figura do monopólio (que, no caso da América portuguesa, não impediu acirrada concorrência entre comerciantes metropolitanos); os "superlucros"

comerciais. Eles envolvem múltiplas dimensôes da chamada "Troca Colombiana", composta, entre outros, de fluxos de doença, alimentos e ideias, com óbvios impactos sobre as economias do Novo e Velho mundos. Para este ponto, ver NUNN, Nathan; QIAN, Nancy. The Columbian Exchange: a history of disease, food, and ideas. Journal of Economic Perspectives, v. 24, n. 2, p. 163-188, Spring 2010. 
(que, da forma como calculados por Arruda, são, na verdade, elevados diferenciais de preços); e a transferência de tais "lucros" (por vias náo/mal explicadas pelos adeptos do Modelo) para a Inglaterra, onde teriam ajudado a financiar a Revoluçáo Industrial.

Para concluir, sou muito grato ao Prof. Jobson pelos comentários a meu artigo. Obrigou-me a pensar melhor sobre diversos pontos de meu próprio argumento, voltar à literatura relevante e, em alguns casos, esclarecer passagens que não estavam suficientemente claras em meu trabalho. Mas continuo sem ser convencido pelo Modelo do Antigo Sistema Colonial. A meu ver, ele não explica adequadamente a dinâmica de funcionamento da economia da América portuguesa. Mais limitada, ainda, é sua capacidade de explicar o (eventual) papel que a exploração colonial do Brasil teve no advento da Revolução Industrial britânica.

\section{Referências Bibliográficas}

ARRUDA, José Jobson de A. Superlucros: a prova empírica do exclusivo colonial. Topoi, v. 15, n. 29, p. 706-718, jul./dez. 2014.

\section{O Brasil no comércio colonial. São Paulo: Ática, 1980.}

BECKERT, Sven. Empire of Cotton: a global history. Nova York: Alfred A. Knopf, 2014. BROADBERRY, Stephen; CAMPBELL, Bruce M. S.; KLEIN, Alexander; OVERTON, Mark; LEUWEN, Bas van. British Economic Growth, 1270-1870. Cambridge: Cambridge University Press, 2015.

DAUDIN, Guillaume. Profitability of Slave and Long-Distance Trading in Context: the case of eighteenth-century France. Journal of Economic History, v. 64, n. 1, p. 144-171, March 2004.

Comment Calculer les Profits de la Traite?. Mimeo, 2002. Disponível em: <http://spire.sciences-po.fr/hdl:/2441/691/resources/cfi-art-gd-outremer2002draft.pdf>. FRAGOSO, João Luís Ribeiro; GOUVÊA, Maria de Fátima (Orgs.). O Brasil colonial. Rio de Janeiro: Civilização Brasileira, 2014.

GELDERBLOM, Oscar. The Organization of Long-Distance Trade in England and the Dutch Republic, 1550-1650. Mimeo, 2008. Disponível em: <http://vkc.library. uu.nl/vkc/seh/research/Lists/Working\%20Papers/Attachments/16/Gelderblom_ OrganizationTrade_2008.pdf >.

HONDA, Laercio M. Francisco Pinheiro: as atividades de um comerciante de grosso trato na América Portuguesa (1703-1749). Dissertação (mestrado) — Instituto de Economia, Unicamp, 2004.

LISANTI, Luis. Negócios coloniais: uma correspondência comercial do século XVIII. Brasília: Ministério da Fazenda; São Paulo: Visão, 1973. 
NUNN, Nathan; QIAN, Nancy. The Columbian Exchange: a history of disease, food, and ideas. Journal of Economic Perspectives, v. 24, n. 2, p. 163-188, Spring 2010.

O'BRIEN, Patrick. The Formation of States and Transitions to Modern Economies: England, Europe, and Asia compare. In: NEAL, Larry; WILLIAMSON, Jeffrey (Orgs.). The Cambridge History of Capitalism. Cambridge: Cambridge University Press, v. I (The Rise of Capitalism: from Ancient Origins to 1848), 2014. . Mercantilism and Imperialism in the Rise and Decline of the Dutch and English Economies. De Economist, n. 148, p. 469-501, 2000. . Inseparable Connections: Trade, Economy, Fiscal State and the Expansion of Empire, 1688-1815. In: MARSHALL, P. J. (Org.). The Oxford History of the British Empire, v. 2 (The Eighteenth Century). Oxford: Oxford University Press, 1998.

PALMA, Nuno. Sailing Away from Malthus: intercontinental trade and European economic growth, 1500-1800. London School of Economics and Political Science. Economic History Working Papers, n. 210, 2014.

VILLELA, André A. Exclusivo metropolitano, "superlucros" e acumulação primitiva na Europa pré-industrial. Topoi, v. 12, n. 23, p. 4-29, jul.-dez. 2011.

de VRIES, Jan; van der WOUDE, Ad. The First Modern Economy: success, failure, and perseverance of the Dutch economy, 1500-1815. Cambridge: Cambridge University Press, 1997. 